\title{
Differences between genetic dilated cardiomyopathy and myocarditis in children presenting with severe cardiac dysfunction.
}

\author{
Ferran Gran ( $\nabla$ fgran@vhebron.net ) \\ Hospital Vall d'Hebron https://orcid.org/0000-0001-9076-241X \\ Andrea Fidalgo \\ Hospital Vall d'Hebron: Vall d'Hebron Hospital Universitari \\ Paola Dolader \\ Vall d'Hebron Hospital: Vall d'Hebron Hospital Universitari \\ Marta Garrido \\ Hospital Vall d'Hebron: Vall d'Hebron Hospital Universitari

\section{Alexandra Navarro} \\ Hospital Vall d'Hebron: Vall d'Hebron Hospital Universitari \\ Jaume Izquierdo-Blasco \\ Hospital Vall d'Hebron: Vall d'Hebron Hospital Universitari \\ Joan Balcells \\ Hospital Vall d'Hebron: Vall d'Hebron Hospital Universitari \\ Marta Codina-Sola \\ Hospital Vall d'Hebron: Vall d'Hebron Hospital Universitari \\ Paula Fernandez-Alvarez \\ Hospital Vall d'Hebron: Vall d'Hebron Hospital Universitari \\ Anna Sabaté-Rotés \\ Hospital Vall d'Hebron: Vall d'Hebron Hospital Universitari \\ Pedro Betrián \\ Hospital Vall d'Hebron: Vall d'Hebron Hospital Universitari \\ Joaquín Fernández-Doblas \\ Hospital Vall d'Hebron: Vall d'Hebron Hospital Universitari \\ Raúl Abella \\ Hospital Vall d'Hebron: Vall d'Hebron Hospital Universitari \\ Ferran Roses-Noguer \\ Hospital Vall d'Hebron: Vall d'Hebron Hospital Universitari
}

\section{Research Article}

Keywords: Paediatric heart failure, Myocarditis, Cardiomyopathy, Endomyocardial biopsy

Posted Date: March 22nd, 2021

DOI: https://doi.org/10.21203/rs.3.rs-262048/v1

License: (a) (i) This work is licensed under a Creative Commons Attribution 4.0 International License. Read Full License

Version of Record: A version of this preprint was published at European Journal of Pediatrics on July 20th, 2021. See the published version at https://doi.org/10.1007/s00431-021-04175-z. 


\section{Abstract}

Background Acute myocarditis is an inflammatory disease of the myocardium, and it can present as severe heart failure in children. Differential diagnosis with genetic cardiomyopathy can be difficult. The objective of this study is to identify patterns of clinical presentation and to assess invasive and non-invasive measures to differentiate patients with acute myocarditis from patients with dilated genetic cardiomyopathy. Material and Methods We performed a retrospective descriptive study of all paediatric patients (0-16 years old) that presented with new-onset heart failure with left ventricle ejection fraction < $35 \%$ in whom we performed an endomyocardial biopsy (EMB) during the period from April 2007 to December 2020. Results The patients were classified into two groups: Group 1 included 17 patients with myocarditis. Group 2 included 9 patients with genetic cardiomyopathy. Findings favouring a diagnosis of myocarditis included a fulminant or acute presentation ( $77.8 \%$ vs $33.3 \%, p=0.01)$, higher degree of cardiac enzyme elevation ( $p=0.011)$, lower left ventricular dimension $z$-score ( 2.2 vs. $5.4, p=0.03$ ) increase of ventricular wall thickness ( $88.8 \%$ vs $33.3 \%, p=0.03$ ), and oedema in the endomyocardial biopsy. Seven (77.8\%) patients with genetic cardiomyopathy had inflammation in the endomyocardial biopsy, fulfilling the diagnostic criteria of inflammatory cardiomyopathy. Conclusions Differentiate patients with a myocarditis from those with genetic cardiomyopathy can be challenging, even performing an EMB. Some patients with genetic cardiomyopathy fulfil the diagnostic criteria of inflammatory cardiomyopathy. Using invasive and non-invasive measures may be useful to develop a predictive model to differentiate myocarditis from genetic cardiomyopathy.

\section{Introduction}

Acute myocarditis is an inflammatory disease of the myocardium that can present with cardiogenic shock requiring mechanical circulatory assistance ${ }^{1,2}$. In our environment, the most frequent cause is a viral infection, especially parvovirus B19 (PVB19) ${ }^{1,3}$. The gold standard diagnostic test is the endomyocardial biopsy (EMB), although since it is an invasive and risky procedure ${ }^{4,5}$, its use is limited in paediatric patients. The Dallas histological diagnostic criteria ${ }^{6}$ have shown to have low sensitivity and high inter-observer variability ${ }^{7}$. Therefore, new immunohistochemical criteria ( $\geq 14$ white blood cells / $\mathrm{mm}^{2}$ and $\geq 7 \mathrm{CD} 3 \mathrm{~T}$ lymphocytes $/ \mathrm{mm}^{2}$ ) have been proposed ${ }^{3,8}$.

Although most patients with myocarditis have a complete recovery, there are still $20-30 \%$ of them that can develop dilated cardiomyopathy ${ }^{3,8,9,10}$. It has been reported that $50-60 \%$ of adults $8,9,10,11$ and $46 \%$ of children ${ }^{8,9}$ with dilated cardiomyopathy have evidence of inflammation or viral genome in the heart, suggesting previous viral myocarditis. These patients could benefit from immunosuppressive or antiviral treatment ${ }^{8,12-14}$. Nevertheless, it is known that some patients with genetic cardiomyopathy can present inflammatory infiltrates ${ }^{10,15}$ and the presence of a viral genome in the myocardium has been found in patients without cardiomyopathy ${ }^{16}$. Still, these findings do not always imply an active infection. Differentiation between inflammatory dilated cardiomyopathy secondary to a previous myocarditis versus genetic dilated cardiomyopathy might be very challenging, but it has important implications both for prognosis and to establish the appropriate treatment ${ }^{17}$.

The objective of this study is to describe the clinical presentation, laboratory results, echocardiographic details, ECG findings and EMB characteristics in a group of children who presented with a severe cardiac dysfunction with a LVEF $<35 \%$ and to describe potential factors to help differentiate patients with acute myocarditis from patients with dilated genetic cardiomyopathy.

\section{Material And Methods}

We performed a retrospective descriptive study including all paediatric patients ( $0-16$ years) that presented with new-onset heart failure, with a left ventricular ejection fraction (LVEF) $<35 \%$, who underwent an EMB during the period from April 2007 to December 2020. The investigation conforms with the principles outlined in the Declaration of Helsinki" (Br Med J 1964; ii: 177) and obtained approval by our local ethics committee. The patients were divided retrospectively into two groups: group 1 included all patients with $\geq 14$ white blood cells $/ \mathrm{mm}^{2}$ and $\geq 7$ CD3 T lymphocytes / $\mathrm{mm}^{2}$ in the EMB, indicating the presence of myocardial inflammation in whom a) a definitive diagnosis of myocarditis was performed after a typical clinical course or b) those in whom the genetic study did not find any pathogenic mutation associated with cardiomyopathy ; group 2 included all patients in whom a definitive pathogenic genetic mutation associated with dilated cardiomyopathy was found.

Data on personal medical history, clinical outcomes and medical treatment were recorded. Clinical presentation was defined as acute (symptoms of heart failure were present $\leq 15$ days before admission) or subacute ( $>15$ days). A positive family history was considered when there was history of sudden death or cardiomyopathy in a first-degree realtive. We collected histological and immunohistochemical findings in the EMB samples, viral polymerase chain reaction (PCR) in the heart and blood, troponin levels, brain natriuretic peptide, and respiratory secretions, 12-lead electrocardiogram(ECG) and transthoracic echocardiogram data. Also, in all haemodynamically stable patients, a cardiac magnetic resonance (CMR) was performed.

Endomyocardial Biopsy

According to our protocol, EMB was performed to all patients $\geq$ six months and $\geq 8 \mathrm{~kg}$ of weight with a new-onset ventricular dysfunction of unknown origin, who presented with: a) LVEF < 35\% and need for extracorporeal oxygenation membrane(ECMO); b) LVEF < 35\% with a haemodynamic compromise without ECMO but with no echocardiographic improvement after more than one week of medical treatment; c) patients with LVEF $<35 \%$ that remained hemodynamically stable but without any significant improvement after $>2$ weeks of medical treatment.

The EMB was performed through jugular access with a $6 \mathrm{Fr}$ bioptome, and 6 samples were obtained from the right interventricular septum. Four were sent to pathology examination and 2for microbiology. Haematoxylin-eosin and Mason's trichrome stains and immunohistochemical stains for CD45, CD20, CD3, and CD68, were performed. We used immunohistology criteria of $\geq 14$ mononuclear cells with $\geq 7$ CD3 lymphocytes per $\mathrm{mm}^{2}$ for diagnosis of myocarditis. 
In those patients $<6$ months or $<8 \mathrm{~kg}$ the decision to perform an EMB was made individually.

Cardiac Magnetic Resonance

CMR studies were performed using a 1.5T Magnetom Avanto, Siemens Medical System, Erlangen, Germany, with cardiac synchronisation. The sequences used were white blood sequences (SSFP) to assess ventricular function, T2-weighted sequences (T2W-STIR), T1 sequences (TSE) before and after the administration of intravenous contrast and delayed uptake of the contrast (PSIR-SSFP). We used gadolinium as contrast with a dose of $0.1-0.2 \mathrm{mmol} / \mathrm{kg}$. For the diagnosis of acute myocarditis, the Lake-Louise criteria were used ${ }^{18}$.

Genetic testing

Genomic DNA was isolated from peripheral blood following standard procedures. Genetic testing was performed on a MiSeq sequencer using the TruSight Cardio Panel, which includes exonic and flanking intronic regions of 174 genes related to cardiovascular disorders. Variant classification was performed according to the guidelines established by the American College of Medical Genetics and Genomics ${ }^{19}$. In those patients who presented with a typical fulminant course of myocarditis ${ }^{20}$ and had a complete recovery, genetic testing was not performed as was thought not to be clinically indicated. Thus, these patients were included in group 1.

\section{Statistical analysis}

Statistical analyses were performed with SPSS version 18.0.0 (IBM Corporation, Armonk, NY). Data are presented as count (percentage) and mean \pm SD value or median (range) were appropriate. Categorical data were compared using the Mantel-Haenszel Chi-square test (X2). In case of not complying with its application norms (expected frequency $<5$ ), Fisher's F test was used with the continuity correction. Differences in continuous variables were analysed using independent Student T-testor Mann-Whitney test when applicable. A level of statistical significance with $p<0.05$ was considered.

\section{Results}

Twenty-seven patients with a median age of 26 months (0-194) and 55.5\% (15/27) female gender were included (Table 1). Eighteen patients were included in group 1 (myocarditis) and 9 patients in group 2 (genetic cardiomyopathy). Among those patients with myocarditis,77.7\% had a previous history of viral infection and presented a shorter history of symptoms (Table 2). Viral PCR in blood was positive in 50\% (9/18) of myocarditis episodes, but it was also positive in $33 \%(3 / 9)$ of patients with genetic cardiomyopathy $(p=0.431)$. Patients with myocarditis had a higher elevation of troponin levels $(p=0.011)$ with no differences seen between pro-BNP levels. In the echocardiogram, left ventricle trabeculations were seen in $44 \%$ of patients with genetic cardiomyopathy, but were also present in $11.1 \%(2 / 18, p=0.136)$ of patients with myocarditis. The LVEDD Z-Score was significantly lower in patients with myocarditis $(2.2$ vs 5.4 , $p=0.03)$, and they had an increased ventricular wall thickness ( $88.8 \%$ vs $33.3 \%, p=0.03)$. Amongst patients that underwent a CMR, $37.5 \%(3 / 8)$ in group 1 and $33.3 \%(2 / 6)$ in group 2, fulfilled 2/3Lake Louis Criteria $(p=1)$. The presence of inflammatory infiltrate was higher in patients with myocarditis (37.5 (8-180) vs $\left.14(0-24) \mathrm{CD} 3 / \mathrm{mm}^{2}\right)$ although no significant differences were found $(\mathrm{p}=0.1)$. Nine (50\%) patients in group 1 met Dallas criteria ${ }^{6}$ compared to only $1(11.1 \%)$ in group 2 ( $p=0.09$ ). Immunohistochemical criteria of inflammatory cardiomyopathy ${ }^{8}\left(\geq 14\right.$ white blood cells $/ \mathrm{mm}^{2}$ and $\geq 7 \mathrm{CD} 3 \mathrm{~T}$ lymphocytes $/ \mathrm{mm}^{2}$ ) were fulfilled by $7 / 9(77.7 \%)$ of patients in group 2. Oedema was not seen in any patient with genetic cardiomyopathy, whereas in the myocarditis group, oedema was seen in $12(66.6 \%)$ out of 18 patients $(p=0.01)$. Viral PCR was positive in $9(50 \%)$ heart samples of patients with myocarditis and $2(22.2 \%)$ of patients with genetic cardiomyopathy $(p=0.183)$. PVB19, alone or in coinfection with Human Herpesvirus 6 (HHV6), was found in 10/11 samples $(90.1 \%)$. 
Table 1

Description of patients included in the study including clinical description, infectious results, genetic results and clinical outcomes.

\begin{tabular}{|c|c|c|c|c|c|c|c|c|c|c|c|}
\hline Case & Diagnosis & Gender & $\begin{array}{l}\text { Age } \\
\text { (months) }\end{array}$ & $\begin{array}{l}\text { History } \\
\text { of recent } \\
\text { infection }\end{array}$ & $\begin{array}{l}\text { Clinical } \\
\text { presentation }\end{array}$ & $\begin{array}{l}\text { Genetic } \\
\text { test }\end{array}$ & $\begin{array}{l}\text { CD3 } \\
\text { Lymfocyte/mm2 }\end{array}$ & $\begin{array}{l}\text { Heart } \\
\text { PCR }\end{array}$ & $\begin{array}{l}\text { Blood } \\
\text { PCR }\end{array}$ & $\begin{array}{l}\text { Respiratory } \\
\text { tract PCR }\end{array}$ & Outcome \\
\hline 1 & Miocarditis & Female & 1 & No & Fulminant & ND & 35 & CMV & CMV & Negative & Exitus \\
\hline 2 & Miocarditis & Male & 25 & Yes & Acute & Negative & 40 & PVB19 & $\begin{array}{l}\text { PVB19 y } \\
\text { HHV } 6\end{array}$ & Negative & Healing \\
\hline 3 & Miocarditis & Female & 7 & Yes & Acute & Negative & 15 & PVB19 & Negative & Negative & Transpla \\
\hline 4 & Miocarditis & Male & 27 & Yes & Acute & Negative & 80 & PVB19 & PVB19 & Negative & Healing \\
\hline 5 & Miocarditis & Male & 79 & Yes & Acute & ND & 70 & Negative & Difteria & Difteria & Exitus \\
\hline 6 & Miocarditis & Female & 36 & Yes & Acute & Negative & 50 & PVB19 & PVB19 & Negative & Healing \\
\hline 7 & Miocarditis & Male & 26 & Yes & Acute & Negative & 20 & Negative & Negative & SRV & Healing \\
\hline 8 & Miocarditis & Male & 10 & Yes & Acute & Negative & 25 & $\begin{array}{l}\text { PVB19 } \\
+ \text { HHV } 6\end{array}$ & PVB19 & Negative & Healing \\
\hline 9 & Miocarditis & Male & 22 & No & Acute & Negative & 15 & PVB19 & $\begin{array}{l}\text { PVB19 } \\
+ \text { HHV } 6\end{array}$ & Negative & Healing \\
\hline 10 & Miocarditis & Female & 91 & Yes & Fulminant & ND & 15 & Negative & Negative & Influenza A & Healing \\
\hline 11 & Miocarditis & Female & 109 & Yes & Fulminant & ND & 8 & Negative & Negative & Influenza A & Healing \\
\hline 12 & Miocarditis & Male & 194 & No & Subacute & Negative & 8 & Negative & Negative & Negative & Healing \\
\hline 13 & Miocarditis & Female & 0 & No & Fulminant & Negative & 65 & Negative & Negative & Negative & Exitus \\
\hline 14 & Miocarditis & Female & 92 & Yes & Fulminant & ND & 10 & Negative & Negative & Influenza B & Healing \\
\hline 15 & Miocarditis & Male & 7 & Yes & Subacute & Negative & 50 & Negative & Negative & Negative & Improve \\
\hline 16 & Miocarditis & Female & 10 & Yes & Subacute & Negative & 70 & PVB19 & PVB19 & Negative & Improve \\
\hline 17 & Miocarditis & Female & 39 & Yes & Subacute & Negative & 180 & PVB19 & PVB19 & Negative & Improve \\
\hline 18 & Miocarditis & Female & 142 & Yes & Fulminant & ND & 75 & Negative & Negative & SARS-2 & Healing \\
\hline 15 & GeneticDCM & Male & 2 & No & Acute & MYBPC3 & 4 & Negative & Negative & Negative & Transpla \\
\hline 16 & $\begin{array}{l}\text { Genetic } \\
\text { DCM }\end{array}$ & Male & 99 & Yes & Subacute & DES & 24 & Negative & Negative & Negative & Transpla \\
\hline 17 & $\begin{array}{l}\text { Genetic } \\
\text { DCM }\end{array}$ & Male & 6 & No & Acute & TPM1 & 2 & Negative & Negative & Negative & Transpla \\
\hline 18 & $\begin{array}{l}\text { Genetic } \\
\text { DCM }\end{array}$ & Female & 109 & No & Subacute & TNNT2 & 10 & Negative & Negative & Negative & Transpla \\
\hline 19 & $\begin{array}{l}\text { Genetic } \\
\text { DCM }\end{array}$ & Male & 187 & Yes & Subacute & MYBPC3 & 15 & PVB19 & Negative & Negative & Transpla \\
\hline 20 & $\begin{array}{l}\text { Genetic } \\
\text { DCM }\end{array}$ & Female & 11 & Yes & Acute & TNNI3 & 11 & PVB19 & PVB19 & Negative & Transpla \\
\hline 21 & $\begin{array}{l}\text { Genetic } \\
\text { DCM }\end{array}$ & Female & 30 & No & Subacute & TNNI3 & 14 & Negative & CMV & Adenovirus & LVD \\
\hline 22 & $\begin{array}{l}\text { Genetic } \\
\text { DCM }\end{array}$ & Female & 26 & Yes & Subacute & MYH7 & 18 & Negative & Negative & Influenza A & Transpla \\
\hline 23 & $\begin{array}{l}\text { Genetic } \\
\text { DCM }\end{array}$ & Female & 11 & No & Subacute & SDHAp & 20 & Negative & CMV & Negative & LVD \\
\hline
\end{tabular}

DCM: Dilated Cardiomyopathy, ND: Not done, PCR: Polymerase chain reaction, CMV: Citomegalovirus, PVB19: Parvovirus B19, SRV: Sincitial respiratory virus, LVD: Left ventricular disfunction 
Table 2

Clinical caractheristics of patients with Myocarditis compared with patients with Genetic Cardiomyopathy.

\begin{tabular}{|c|c|c|c|}
\hline & \multirow{2}{*}{$\begin{array}{l}\text { Acute Myocarditis } \\
18 \text { cases }\end{array}$} & \multirow{2}{*}{$\begin{array}{l}\text { Genetic Miocardiopathy } \\
9 \text { cases }\end{array}$} & \multirow[t]{2}{*}{ Statistical significance } \\
\hline & & & \\
\hline Age(months) & $26.5(0-194)$ & $26(2-187)$ & $p=1$ \\
\hline Male gender & $44.4 \%(8)$ & $55.6 \%(5)$ & $p=0.795$ \\
\hline History of family heart disease & $0 \%(0)$ & $33.3 \%(3)$ & $p=0.021$ \\
\hline History of recent infection & $77.7 \%(14)$ & $44.4 \%(4)$ & $p=0.083$ \\
\hline \multirow[t]{3}{*}{ Clinical presentation } & Fulminant & Fulminant & \multirow[t]{3}{*}{$p=0.01$} \\
\hline & $44.4 \%(8)$ & $33.3 \%(3)$ & \\
\hline & Subacute & Subacute & \\
\hline ECMO & $55.5 \%(10)$ & $33.3 \%(3)$ & $p=0.147$ \\
\hline Troponine elevation & $60(1.1-2950)$ & $2.2(0.25-16)$ & $p=0.011$ \\
\hline Pro-BNP & 1498 ng/ml (459-53500) & 4221 ng/ml (278-23804) & $p=0.315$ \\
\hline Blood PCR & $50 \%(9)$ & $33.3 \%(3)$ & $p=0.431$ \\
\hline \multicolumn{4}{|l|}{ Echocardiogram } \\
\hline LVEF (\%) & $24.6 \%( \pm 6,18)$ & $23.4 \%( \pm 6,17)$ & $p=0.846$ \\
\hline LVTDD Z-score & $+2.2 \mathrm{DS}(0-10)$ & $+5.4 \mathrm{DS}(+3,2-10,4)$ & $p=0.03$ \\
\hline LV hypertrophy & $88.8 \%(16)$ & $33.3 \%(3)$ & $p=0.03$ \\
\hline Trabeculation & $11.1 \%(2)$ & $44.4 \%(4)$ & $p=0.136$ \\
\hline RV disfunction & $50 \%(9)$ & $55.5 \%(5)$ & $p=0.35$ \\
\hline \multicolumn{4}{|l|}{ ECG } \\
\hline Low voltages & $66.6 \%(12)$ & $33 \%(3)$ & $p=0.127$ \\
\hline CMR Lake-Louise & $37.5 \%(3 / 8)$ & $33.3 \%(2 / 6)$ & $p=1$ \\
\hline \multicolumn{4}{|l|}{ EMB } \\
\hline Dallas Criteria & $50 \%(9)$ & $11.1 \%(1)$ & $p=0.091$ \\
\hline $\mathrm{CD} 3 / \mathrm{mm} 2$ & $37.5(8-180)$ & $14(2-24)$ & $p=0.1$ \\
\hline Oedema & $66.6 \%(12)$ & $0 \%(0)$ & $p=0.001$ \\
\hline Necrosis & $50 \%(9)$ & $11.1 \%(1)$ & $p=0.091$ \\
\hline Fibrosis & $44 \%(8)$ & $55.5 \%(5)$ & $p=0.94$ \\
\hline Hypertrophy & $5.5 \%(1)$ & $44.4 \%(4)$ & $p=0.03$ \\
\hline Heart PCR & $50 \%(9)$ & $22.2 \%(2)$ & $p=0.183$ \\
\hline \multicolumn{4}{|l|}{ Outcome } \\
\hline Complete Recovery & $71.4 \%(10)$ & $0 \%(0)$ & \multirow[t]{2}{*}{$p=0.021$} \\
\hline Exitus/transplant & $22.2 \%(4)$ & $77.8 \%(7)$ & \\
\hline
\end{tabular}

Ten (55.5\%) patients with myocarditis required ECMO, of which 8/10 (80\%) could be weaned and had a complete recovery. Only 1 patient required mechanical circulation assistance with a Berlin-Heart ${ }^{\circledR}$ as a bridge to heart transplant. On the other hand, 3 patients required ECMO and 2 Berlin-Heart ${ }^{\circledR}$ in group 2 , and none of them recovered. After a follow-up time of 45 months (2-238), 77.7\% of patients with acute myocarditis had a complete recovery, while $3(16.6 \%)$ died in the acute phase. In group 2, there were no deaths, but $7 / 9$ (77.8\%) required a heart transplant and none presented a complete recovery (Table 2$)$.

Table 1 describes the most relevant clinical data for each patient. Patient 1 died during the EMB. It was the first case in our centre, and it was performed obtaining the myocardial samples from the right interventricular septum and left ventricle free wall. Since then, all the samples were taken from the right interventricular septum with no further complications. Patient number 5 had diphtheria myocarditis and he developed a severe cerebral haemorrhage while he was supported with ECMO. Patient 17 was an 11-years-old girl who presented with fulminant myocarditis during a SARS-CoV-2 infection. After 5 days on ECMO, she had a complete recovery. 


\section{Discussion}

Acute myocarditis can present with new-onset severe left ventricular dysfunction, and differential diagnosis with a genetic dilated cardiomyopathy should be considered. In our study, most patients from group 2 (66.6\%) had a subacute clinical presentation (more than 15 days of evolution) whereas most patients from group 1 had a fulminant or acute presentation. Unlike what might be expected, the presence of a family history of genetic cardiomyopathy was infrequent. Troponin values were above the reference values in both groups, but the elevation was higher in patients with myocarditis. All the patients selected in our study had a LVEF of less than $35 \%$. Left ventricle end-diastolic diameter was significantly higher in group 2 . The presence of trabeculations that met non-compaction criteria was more common in group $2(44.4 \%)$, but it was also seen in 2 patients (11.1\%) from group 1 ( $p=0.136)$. These 2 patients had a subacute presentation, with a history of PVB19 infection several weeks before heart failure and PVB19 PCR was positive in blood and heart samples. Genetic test was negative in both, and there was no family history of cardiomyopathy. Thus, LV trabeculations seen in these patients could be the result of a LV remodelling process. Hypertrophy of the septum or posterior wall of the LV was more frequent in patients with myocarditis $(88.8 \%$ vs $33.3 \%, p=0.03)$, and this finding is likely to be associated with myocardial oedema.

In our experience, CMR sensitivity in paediatric patients with myocarditis, is low in cardiomyopathic clinical presentation. This fact has been previously described in adult patients ${ }^{21}$. In our study, we could perform a CRM in only 14 patients due to hemodynamic instability on admission. In the myocarditis group, $7 / 8$ patients (87.8\%) met at least 1 of the Lake Louise criteria, but only 3 patients (37.5\%) met 2/3, a necessary condition for making the diagnosis. Interestingly, we also found 2 out of 6 patients in group 2 (33.3\%) that underwent a CMR that also met 2/3 Lake Louise criteria for myocarditis. This finding has also been recently described by Martins et $\mathrm{al}^{22}$.

The current gold standard test for the diagnosis of myocarditis is the EMB but is a risky technique ${ }^{4,5}$ in paediatric patients and is not widely used. In our experience, the rate of complications is low when performed in patients $\geq$ six months and $\geq 8 \mathrm{~kg}$ and the samples are taken from the right ventricular septum.

Suthar et $\mathrm{al}^{17}$ published a remarkably interesting study in which they assessed the utility

of non-invasive measures to distinguish myocarditis from other forms of dilated cardiomyopathy in paediatric patients. They establish the diagnosis of myocarditis based on Dallas criteria. In our experience, these criteria ${ }^{6}$ are of limited use, as only $50 \%$ of patients with myocarditis fulfilled them. Despite this, some of our results are similar. In addition, we describe the most common findings in EMB. Current immunohistology criteria ${ }^{8}$ have not been validated in the paediatric population. We observed a high rate of false positives, given that $77.8 \%$ of the patients with genetic cardiomyopathy presented $\geq 14$ mononuclear cells $/ \mathrm{mm}^{2}$ with $\geq 7 \mathrm{CD} 3$ lymphocytes $/ \mathrm{mm}^{2}$ in the EMB. One possible explanation for these findings could be that these patients had concurrent acute myocarditis. In our opinion, a more plausible explanation is that myocardial inflammation can be triggered by acute clinical decompensation with severe cardiac dysfunction in individuals with genetic cardiomyopathy. This theory has also been proposed recently by Ammirati et al. ${ }^{23}$.

Although the number of lymphocytes $/ \mathrm{mm}^{2}$ was higher in group $1\left(37.5(8-180)\right.$ vs $\left.14(0-24) \mathrm{CD} 3 / \mathrm{mm}^{2}, \mathrm{p}=0.1\right)$, no significant differences were found. Some patients in group 1 had a minor infiltrate, and this could be due to the patchy nature of the disease. Interestingly, a recent paper from Ukimuraet al. reported that myocarditis secondary to influenza viruses could present a clinical picture of fulminant myocarditis with very mild histological changes ${ }^{24}$. In our study, 3 cases had influenza (patients 9, 10 and 13), and all of them had very mild histological changes. If those patients were excluded from the analysis, the number of lymphocytes $/ \mathrm{mm}^{2}$ would have been significantly higher in the myocarditis group (53 (8-180) CD3/mm ${ }^{2}$ vs $\left.14(0-24), p=0.009\right)$. Then the differences in both groups would become statistically significant. Myocardial oedema in the EMB was observed in $66.6 \%$ of patients in group 1 and none of group 2 ( $p=$ 0.001), suggesting that it could be a specific marker of myocarditis. On the other hand, myocyte hypertrophy was more likely in patients with genetic cardiomyopathy $(5.5 \%$ vs $44.4 \%, p=0.03)$. The latter, we believe, was an unspecific finding associated with a long-standing clinical picture.

In our patients, PVB19 was the main responsible for acute myocarditis, as has been described before ${ }^{1,3}$. Despite this, myocardial PCR only had a $50 \%$ sensitivity, with a $22.2 \%$ rate of false-positive cases. The detection of viral genome in the heart of patients without cardiomyopathy has also been previously described $^{16}$. The usefulness of the blood PCR was greater in younger patients (Table 1), especially in children under 5 years of age.

Mortality during the acute phase of illness was higher in patients from group $1(16.6 \%$ vs $0 \%, p=0.021)$ and $55.5 \%$ required ECMO support on admission. If patients survived the initial stage, the long-term survival was excellent. Thus, $92.8 \%$ of cases of myocarditis who survived the initial stage, had a complete recovery. In the other hand, patients from group 2 had $0 \%$ acute mortality, had a non-fulminant clinical presentation. Still, recovery is rare, and only $22 \%$ were free of transplant at the end of follow-up time.

\section{Conclusions}

Our study suggests that current diagnostic criteria for myocarditis have limited use in paediatric patients presenting with new-onset heart failure and LVEF < $35 \%$. Some patients with genetic cardiomyopathy fulfil diagnostic criteria of inflammatory cardiomyopathy. Thus, familiar, and genetic study is recommended in paediatric patients with acute and subacute new onset-heart failure. Acute myocarditis is a suspected diagnosis where no examination by itself, is sensitive and specific enough. Using invasive and non-invasive measures may be useful to develop a predictive model to differentiate myocarditis from genetic cardiomyopathy.

\section{Study Limitations}

The main limitation of our study is the small number of patients. Despite this, our cohort is one of the published series with a higher number of paediatric patients with myocarditis that underwent EMB. Furthermore, the observed effects should be applied only to patients with a severe form of presentation with 
LVEF $<35 \%$. We cannot rule out that some of the patients with a genetic mutation might have, at the same time, acute myocarditis. In the same way, some of the patients with acute myocarditis could also have a genetic condition of unknown origin to date.

\section{Declarations}

\section{Study limitations}

The main limitation of our study is the small number of patients. Despite this, our cohort is one of the published series with a higher number of paediatric patients with myocarditis that underwent EMB. Furthermore, the observed effects should be applied only to patients with a severe form of presentation with LVEF $<35 \%$. We cannot rule out that some of the patients with a genetic mutation might have, at the same time, acute myocarditis. In the same way, some of the patients with acute myocarditis could also have a genetic condition of unknown origin to date.

\section{Funding}

Authors declare that no funding was obtained for this article.

\section{Conflict of interest}

Conflict of Interest: none declared.

\section{Ethics approval}

The study complies with the Declaration of Helsinki, and the locally appointed ethics committee has approved the research protocol, and informed consent has been obtained from the subjects (or their guardians).

\section{References}

1. Molina KM, Garcia X, Denfield SW, Fan Y, Morrow WR, Towbin JA, Frazier EA, Nelson DP. Parvovirus B19 myocarditis causes significant morbidity and mortality in children. PediatrCardiol 2013; 34:390-397.

2. Hsu KH, Chi NH, Yu HY, et al. Extracorporeal membranous oxygenation support for acute fulminant myocarditis: analysis of a single center's experience. Eur J CardiothoracSurg. 2011; 40:682-688.

3. Dominguez F, Kühl U, Pieske B, Garcia-Pavia P, Tschöpe C. Update on Myocarditis and Inflammatory Cardiomyopathy: Reemergence of Endomyocardial Biopsy. Rev Esp Cardiol (Engl Ed). 2016 Feb;69(2):178-87.

4. Zhorne D, Petit CJ, Ing FF, Justino H, Jefferies JL, Dreyer WJ, Kearney D, Crystal MA. A 25- year experience of endomyocardial biopsy safety in infants. Catheter Cardiovasc Interv. 2013 Nov 1;82(5):797-801.

5. Mills KI, Vincent JA, Zuckerman WA, Hoffman TM, Canter CE, Marshall AC, Blume ED, Bergersen L, Daly KP. Is Endomyocardial Biopsy a Safe and Useful Procedure in Children with Suspected Cardiomyopathy? Pediatr Cardiol. 2016 Oct;37(7):1200-10

6. Aretz HT, Billingham ME, Edwards WD, Factor SM, Fallon JT, FenoglioJJ Jr, Olsen EG, Schoen FJ. Myocarditis: a histopathologic definition and classification. Am J CardiovascPathol. 1987; 1:3-14.

7. Baughman KL. Diagnosis of myocarditis: death of Dallas criteria. Circulation. 2006; 113:593-595.

8. Caforio AL, Pankuweit S, Arbustini E, Basso C, Gimeno-Blanes J, Felix SB, Fu M, Heliö T, Heymans S, Jahns R, Klingel K, Linhart A, Maisch B, McKenna W, Mogensen J, Pinto YM, Ristic A, Schultheiss HP, Seggewiss H, Tavazzi L, Thiene G, Yilmaz A, Charron P, Elliott PM. Current state knowledge on aetiology, diagnosis, management, and therapy of myocarditis: a position statement of the European Society of CardiologyWorking Group on Myocardial and Pericardial Diseases. EuropeanHeartJournal (2013) 34, 2636-2648.

9. Katzmann JL, Schlattmann P, Rigopoulos AG, Noutsias E, Bigalke B, Pauschinger M, Tschope C, Sedding D, Schulze PC, Noutsias M. Meta-analysis on the immunohistological detection of inflammatory cardiomyopathy in endomyocardial biopsies. Heart Fail Rev. 2020 Mar;25(2):277-294.

10. Imanaka-Yoshida K. Inflammation in myocardial disease: From myocarditis to dilated cardiomyopathy. Pathol Int. 2020 Jan;70(1):1-11.

11. Kühl U, Pauschinger M, Noutsias M, Seeberg B, Bock T, Lassner D, Poller W, Kandolf R, Schultheiss HP. High prevalence of viral genomes and multiple viral infections inthemyocardium of adults with"idiopathic" leftventricular dysfunction. Circulation 2005 Feb 22;111(7):887-93.

12. Frustaci A, Russo MA, Chimenti C. Randomizedstudy on the efficacy of immunosuppressive therapy in patients with virus-negative inflammatory cardiomyopathy: the TIMIC study. Eur Heart J. 2009; 30:1995-2002.

13. Kühl U, Pauschinger M, Schwimmbeck PL, Seeberg B, Lober C, Noutsias M, Poller W, Schultheiss HP. Interferon- $\beta$ Treatment Eliminates Cardiotropic Viruses and Improves Left Ventricular Function in Patients With Myocardial Persistence of Viral Genomes and Left Ventricular Dysfunction. Circulation. 2003; 107:2793-8.

14. Schultheiss HP, Piper C, Sowade O, Waagstein F, Kapp JF, Wegscheider K, Groetzbach G. Betaferon in chronic viral cardiomyopathy (BICC) trial: Effects of interferon-b treatment in patients with chronic viral cardiomyopathy. Clin Res Cardiol (2016) 105:763-773.

15. Asimaki A1, Saffitz JE. The role of endomyocardial biopsy in ARVC: looking beyond histology in search of new diagnostic markers. J Cardiovasc Electrophysiol. 2011 Jan;22(1):111-7.

16. Verdonschot J, Hazebroek M, Merken J, Debing Y, Dennert R, Brunner-La Rocca HP, Heymans S. Relevance of cardiac Parvovirus B19 in myocarditis and dilated cardiomyopathy: review of the literature. Eur J Heart Fail. 2016 Dec; 18(12):1430-1441. 
17. Suthar D, Dodd DA, Godown J. Identifying Non-invasive Tools to Distinguish Acute Myocarditis from Dilated Cardiomyopathy in Children. Pediatr Cardiol. 2018 Aug;39(6):1134-1138.

18. Friedrich MG, Sechtem U, Schulz-Menger J, Holmvang G, Alakija P, Cooper LT, White JA, Abdel-Aty H, Gutberlet M, Prasad S, Aletras A, Laissy JP, Paterson I, Filipchuk NG, Kumar A, Pauschinger M, Liu P; International Consensus Group on Cardiovascular Magnetic Resonance in Myocarditis. Cardiovascular Magnetic Resonance in Myocarditis: A JACC White Paper. J Am Coll Cardiol. 2009 Apr 28;53(17):1475-8.

19. Richards S, Aziz N, Bale S, Bick D, Das S, Gastier-Foster J, Grody WW, Hegde M, Lyon E, Spector E, Voelkerding K, Rehm HL. Standards and guidelines for the interpretation of sequence variants: a joint consensus recommendation of the American College of Medical Genetics and Genomics and the Association for Molecular Pathology. Genet Med. 2015 May;17(5):405-24.

20. Lieberman EB, Hutchins GM, Herskowitz A, Rose NR, Baughman KL. Clinicopathologic description of myocarditis. J Am Coll Cardiol 1991; 18: 1617-2

21. Francone M, Chimenti C, Galea N, Scopelliti F, Verardo R, Galea R, Carbone I, Catalano C, Fedele F, Frustaci A. CMR sensitivity varies with clinical presentation and extent of cell necrosis in biopsy-proven acute myocarditis. JACC Cardiovasc Imaging. 2014 Mar;7(3):254-63.

22. Martins D, Ovaert C, Khraiche D, Boddaert N, Bonnet D, Raimondi F. Myocardial inflammation Detected by cardiac MRI in Arrhythmogenic right ventricular cardiomyopathy: a paediatric case series. Int. J. Cardiol. 2018; 271:81-6.

23. Ammirati E, Kaski JP. Resident inflammatory cells in the myocardium of children: On the way to set histologic reference standards to differentiate normal myocardium from myocarditis. Int J Cardiol. 2020 Mar 15; 303:64-65.

24. Ukimura A, Satomi H, OoiY, Kanzaki.Myocarditis Associated with Influenza A H1N1 pdm 2009. Influenza Res Treat. 2012; $2012: 351979$.

\section{Tables}

Table 1. Description of patients included in the study including clinical description, infectious results, genetic results and clinical outcomes.

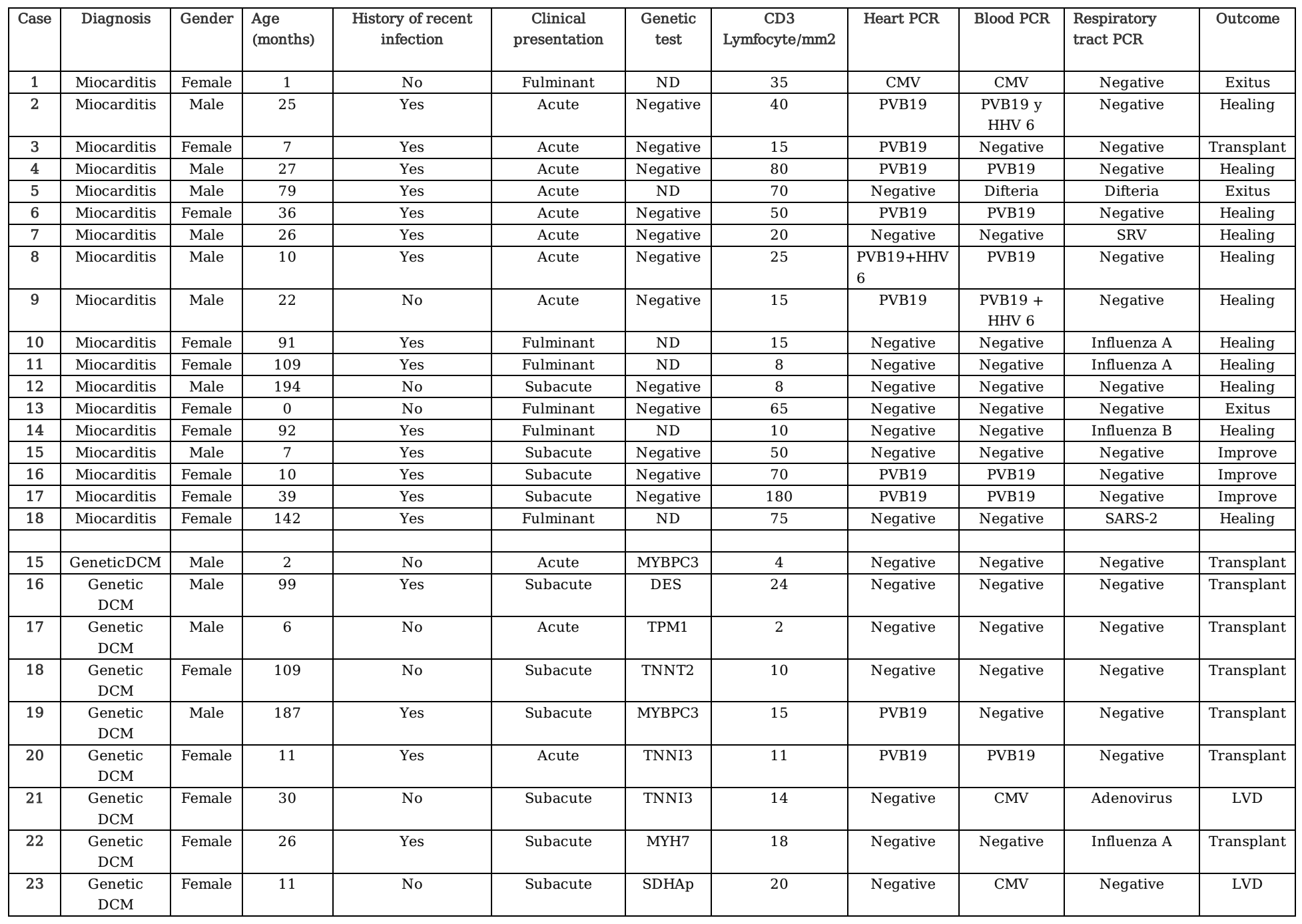

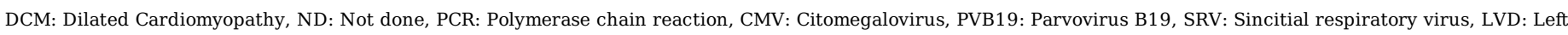
ventricular disfunction 


\begin{tabular}{|c|c|c|c|c|c|}
\hline & \multicolumn{2}{|c|}{$\begin{array}{c}\text { Acute Myocarditis } \\
18 \text { cases }\end{array}$} & \multicolumn{2}{|c|}{$\begin{array}{c}\text { Genetic Miocardiopathy } \\
9 \text { cases }\end{array}$} & Statistical significance \\
\hline Age(months) & \multicolumn{2}{|c|}{$26.5(0-194)$} & \multicolumn{2}{|c|}{$26(2-187)$} & $\mathrm{p}=1$ \\
\hline Male gender & \multicolumn{2}{|c|}{$44.4 \%(8)$} & \multicolumn{2}{|c|}{$55.6 \%(5)$} & $\mathrm{p}=0.795$ \\
\hline History of family heart disease & \multicolumn{2}{|c|}{$0 \%(0)$} & \multicolumn{2}{|c|}{$33.3 \%(3)$} & $\mathrm{p}=0.021$ \\
\hline History of recent infection & \multicolumn{2}{|c|}{$77.7 \%(14)$} & \multicolumn{2}{|c|}{$44.4 \%(4)$} & $\mathrm{p}=0.083$ \\
\hline \multirow[t]{3}{*}{ Clinical presentation } & Fulminant & $30 \%(6)$ & Fulminant & $0 \%(0)$ & \multirow{3}{*}{$p=0.01$} \\
\hline & Acute & $44.4 \%(8)$ & Acute & $33.3 \%(3)$ & \\
\hline & Subacute & $22.2 \%(4)$ & Subacute & $66.7 \%(6)$ & \\
\hline ECMO & \multicolumn{2}{|c|}{$55.5 \%(10)$} & \multicolumn{2}{|c|}{$33.3 \%(3)$} & $\mathrm{p}=0.147$ \\
\hline Troponine elevation & \multicolumn{2}{|c|}{$60(1.1-2950)$} & \multicolumn{2}{|c|}{$2.2 \quad(0.25-16)$} & $\mathrm{p}=0.011$ \\
\hline Pro-BNP & $1498 \mathrm{ng} / \mathrm{m}$ & $459-53500)$ & $4221 \mathrm{ng} / \mathrm{ml}$ & $(278-23804)$ & $\mathrm{p}=0.315$ \\
\hline Blood PCR & \multicolumn{2}{|c|}{$50 \%(9)$} & \multicolumn{2}{|c|}{$33.3 \%(3)$} & $\mathrm{p}=0.431$ \\
\hline \multicolumn{6}{|l|}{ Echocardiogram } \\
\hline LVEF (\%) & \multicolumn{2}{|c|}{$24.6 \%( \pm 6,18)$} & \multicolumn{2}{|c|}{$23.4 \%( \pm 6,17)$} & $\mathrm{p}=0.846$ \\
\hline LVTDD Z-score & \multicolumn{2}{|c|}{$+2.2 \mathrm{DS}(0-10)$} & \multicolumn{2}{|c|}{$+5.4 \mathrm{DS}(+3,2-10,4)$} & $\mathrm{p}=0.03$ \\
\hline LV hypertrophy & \multicolumn{2}{|c|}{$88.8 \%(16)$} & \multicolumn{2}{|c|}{$33.3 \%(3)$} & $\mathrm{p}=0.03$ \\
\hline Trabeculation & \multirow{2}{*}{\multicolumn{2}{|c|}{$11.1 \%(2)$}} & \multicolumn{2}{|c|}{$44.4 \%(4)$} & $\mathrm{p}=0.136$ \\
\hline RV disfunction & & & 55.5 & $\%(5)$ & $\mathrm{p}=0.35$ \\
\hline \multicolumn{6}{|l|}{ ECG } \\
\hline Low voltages & \multirow{2}{*}{\multicolumn{2}{|c|}{$\begin{array}{c}66.6 \%(12) \\
37.5 \%(3 / 8)\end{array}$}} & \multicolumn{2}{|c|}{$33 \%(3)$} & $\mathrm{p}=0.127$ \\
\hline CMR Lake-Louise & & & $33.3 \%$ & $(2 / 6)$ & $\mathrm{p}=1$ \\
\hline EMB & & & & & \\
\hline Dallas Criteria & 50 & (9) & & $.1 \%(1)$ & $\mathrm{p}=0.091$ \\
\hline $\mathrm{CD} 3 / \mathrm{mm} 2$ & & $.5(8-180)$ & & $4(2-24)$ & $\mathrm{p}=0.1$ \\
\hline Oedema & 66.6 & $(12)$ & & $(0)$ & $\mathrm{p}=0.001$ \\
\hline Necrosis & 50 & (9) & 11.1 & $\%(1)$ & $\mathrm{p}=0.091$ \\
\hline Fibrosis & 44 & (8) & 55.5 & $\%(5)$ & $\mathrm{p}=0.94$ \\
\hline Hypertrophy & 5.5 & (1) & 44.4 & $\%(4)$ & $\mathrm{p}=0.03$ \\
\hline Heart PCR & 50 & (9) & 22.2 & $\%(2)$ & $\mathrm{p}=0.183$ \\
\hline Outcome & & & & & \\
\hline Complete Recovery & 71.4 & $(10)$ & $0 \%$ & (0) & $\mathrm{p}=0.021$ \\
\hline Exitus/transplant & 22. & o (4) & 77.8 & $\%(7)$ & \\
\hline
\end{tabular}

Table 2. Clinical caractheristics of patients with Myocarditis compared with patients with Genetic Cardiomyopathy.

ECMO: Extracorporeal membrane oxygenation, Pro-BNP: pro-Brain natriuretic peptid, LVEF: Left ventricle ejection fraction, LVTDD: Left ventricle telediastolic diameter, LV: left ventricle, RV: right ventricle, CMR: Cardiac magnetic resonance imaging PCR: polymerase chain reaction.

\section{Supplementary Files}

This is a list of supplementary files associated with this preprint. Click to download.

- MYOCARDITISVSDILATEDCARDIOMYOPATHY.sav 